García Bacete, F. J., \& Villanueva, L. (2003). Family and ability correlates of academic grades. Psychological Reports, 92, 858-860.

Manuscript submitted for possible publication as Brief Article

Family and ability correlates of academic grades ${ }^{12}$

Authors:

Dr. Francisco-Juan García Bacete \& Dr. Lidón Villanueva Badenes

Developmental, Educational, Social, and Methodological Psychology Department. Universitat Jaume I, Castellón, Spain.

Phone: 07-34-964-729549

1 This research was made possible thanks to Research Grant (DGICYT-PS94-0087) donated by the Spanish Government's Scientific and Technical Research Office

2 Address Correspondence to Dr. Francisco-Juan García Bacete, Universidad Jaume I, Departamento de Psicología Evolutiva, Educativa, Social y Metodología, Campus Riu Sec, 12080-Castellón, Spain or email (fgarcia@psi.uji.es) 


\section{FAMILY AND ABILITY CORRELATES OF ACADEMIC GRADES}

Summary.- In a continuation of Marjoribanks (2001) study, using a sample of 150 seventh grade students, relationships among Family Social Status, Parent Involvement, Parent Cultural Level, Intellectual Ability, and Global Grades were examined. Results showed different predictive models for boys and girls. An important finding is that the predictor variables of grades are different from standardized academic achievement.

In an earlier paper, García and Rosel (2001) assumed that "family characteristics may be influential in pupils' school attainments almost as much as their intellectual ability". We used a Global Achievement measure defined as the average grade in all subjects as a measure of academic achievement. Among family characteristics, Social Status, Parents' Involvement, and Parents' Cultural Level (both perceived by teachers), were included. Intellectual ability was defined by Verbal and Non-verbal Intelligence.

In a comment on our findings, Marjoribanks (2001) suggested that gender and specific academic achievement measures may have been important in our results. He carried out a hierarchical regression which partially supported this hypothesis, finding significant differences associated with specific academic achievement measures. Mathematics Achievement was predicted only by Intellectual Ability, and Language Achievement was predicted both by Family Variables and Intellectual Ability. The hypothesis about pupils' gender was only partially supported. The different family variables were associated for girls (Social Status, Cultural Capital, Parents' Involvement), and the prediction of Word Achievement was better than for boys $\left(R^{2}=34.28 \%\right.$ and $R^{2}=27.34 \%$, respectively). Boys' Mathematics Achievement was predicted better than girls 
$\left(R^{2}=32.55 \%\right.$ and $R^{2}=23.33 \%$, respectively). Intellectual Ability was the best achievement predictor both for boys and girls.

This study is a continuation of the García and Rosel work with additional analysis prompted by Marjoribanks. However, there were some important differences between the studies which may explain the results. While Marjoribanks used a standardized test for measuring academic achievement, we used Grades. To measure Parents' Involvement and Family Cultural Level, Marjoribanks asked questions to the parents, we did the same to the teachers, but Marjoribanks used activity measures, while our variables were based on teachers' perceptions.

Sample included 150 pupils of seventh grade ( 85 boys and 65 girls), their parents, and their teachers (García \& Rosel, 2001). Dependent variable was global achievement.

In the statistical analysis, variables were added to stepwise regression equations in three stages. First, relations for Family Social Status with Intellectual Ability and Academic Achievement were examined (Model 1). In the second stage, the regression models included the measures of Parents' Involvement as perceived by teachers (Model 2). In the third stage, the regression model included Parent Cultural Level as perceived by teachers (Model 3). In Table 1, only significant variables in the models are presented.

Results in Table 1 show that Family Social Status and Intellectual Ability had significant associations with boys' and girls' Academic Grades $\left(R^{2}=31 \%, R^{2}=55 \%\right.$, respectively). Two facts can be noticed in comparison with Marjoribanks (2001). First, the variable Intellectual Ability implies verbal intelligence, very different from the nonverbal intelligence measure used by Marjoribanks. Secondly, Parents`' Occupation was not a significant predictor. When Parents' Involvement was added in model 2, it was related significantly to girls' grades (beta=.24), but not to boys' achievement. When Parental Cultural Level was added in model 3, it contributed an extra $12 \%$ of the 
variance in boys' achievement, a $5 \%$ in entire sample and only $1 \%$ for girls. Parental Cultural Level removed the association of Social Status measures with the entire sample's Grades, and the association of Parents' Involvement with girls' Grades. In three regression models girls' grades were better predicted than boys', but familial variables increase the significantly predicted variance more for boys. That is, the only differences as a function of sex were the absence of Parents' Involvement for boys, and the order of the variables in the regression models.

Very likely, the differences with Marjoribanks' results may correspond to the achievement measures used in each study: global versus specific. However, in our opinion, these differences with Marjoribanks' results could be also explained by our use of grades as a dependent variable versus the scores on standardized tests used by Marjoribanks. Two results are specially linked to this assumption: a) The presence of Verbal Intelligence in our predicting models (versus Non-verbal Intelligence in Marjoribanks' study). b) The most important predicting variable seems to be Parental Cultural Level, therefore, it can be suggested that teachers take into account other than pupils' performance when evaluating their achievement.

Finally, we would like to point out several questions. First, it is necessary to determine which variables define family social status. In our study, Parents' Education (including Fathers' Education and Mothers' Education) was a significant predictor, but Parents' Professional level was non-significant. Secondly, it is important to decide which types of Parents' Involvement we consider: for example, parent involvement at home, teacher-parent communication or parenting style. Third, if we use achievement measures in specific areas, the predicting variables must also be specific. In this sense, Parents Involvement and Family Cultural Capital (present in Marjoribanks’s study), may 
be more related to reading activities and general cultural activities than to mathematics contents. 
TABLE 1

REGRESSION COEFFICIENTS FOR RELATIONSHIPS AMONG FAMILY VARIABLES, INTELLECTUAL ABILITY AND GLOBAL GRADES

\begin{tabular}{|c|c|c|c|c|c|c|c|}
\hline \multirow[t]{3}{*}{ Predictor variable } & \multirow[b]{3}{*}{$\mathrm{n}$} & \multicolumn{4}{|c|}{ Global Grade } & & \\
\hline & & \multicolumn{2}{|c|}{ Model 1} & \multicolumn{2}{|c|}{ Model 2} & \multicolumn{2}{|c|}{ Model 3} \\
\hline & & Beta & $p$ & Beta & $p$ & Beta & $p$ \\
\hline Entire Sample & 150 & & & & & & \\
\hline Parent's Education & & .19 & .006 & .17 & .014 & --- & \\
\hline General Verbal Intelligence & & .54 & .001 & .46 & .001 & .45 & .001 \\
\hline Parent Involvement at Home & & & & .20 & .006 & & \\
\hline Parental Cultural Level & & & & & & .36 & .001 \\
\hline Multiple $R$ & & .62 & & .65 & & .68 & \\
\hline Adjusted $100 R^{2}$ & & 38 & .001 & 41 & .001 & 46 & .001 \\
\hline Boys & 85 & & & & & & \\
\hline Parent's Education & & .27 & .006 & .27 & .006 & .20 & .028 \\
\hline General Verbal Intelligence & & .43 & .001 & .43 & .001 & .33 & .001 \\
\hline Parent Involvement at Home & & & & --- & & --- & \\
\hline Parental Cultural Level & & & & & & .38 & .001 \\
\hline Multiple $R$ & & .57 & & .57 & & .67 & \\
\hline Adjusted $100 R^{2}$ & & 31 & .001 & 31 & .001 & 43 & .001 \\
\hline Girls & 65 & & & & & & \\
\hline Parent's Education & & .39 & .001 & .36 & .001 & .33 & .002 \\
\hline Home size & & -.23 & .017 & -.27 & .006 & -.23 & .015 \\
\hline General Verbal Intelligence & & ........55 & .001 & .44 & .001 & .44 & .001 \\
\hline Parent Involvement at Home & & & & .24 & .001 & --- & \\
\hline Parental Cultural Level & & & & & & .27 & .008 \\
\hline Multiple $R$ & & .75 & & .77 & & .78 & \\
\hline Adjusted $100 R^{2}$ & & 55 & .001 & 57 & .001 & 58 & .001 \\
\hline
\end{tabular}




\section{REFERENCES}

García Bacete, F.J., \& Rosel Remírez, J. (2001) Family and personal correlates of academic achievement. Psychological Reports, 88, 533-547.

Marjoribanks, K. (2001) Family and Ability correlates of Academic Achievement. Psychological Reports, 89, 510-512. 